\title{
Epidemiology of osteoporotic fracture in Moldova and development of a country-specific FRAX model
}

\author{
Alla Zakroyeva ${ }^{1}$ - Olga Lesnyak ${ }^{2}$ - Victor Cazac ${ }^{3}$ - Liliana Groppa ${ }^{3}$ - Eugen Russu ${ }^{3}$ - Lia Chislari ${ }^{3}$ - Larisa Rotaru $^{3}$. \\ Helena Johansson ${ }^{4} \cdot$ Nicholas C. Harvey $^{5} \cdot$ Eugene McCloskey $^{6} \cdot$ Mattis Lorentzon $^{7,8} \cdot$ John A. Kanis ${ }^{4,6}$
}

Received: 24 June 2019 / Accepted: 4 November 2019 / Published online: 28 January 2020

(C) The Author(s) 2020

\begin{abstract}
Summary Retrospective population-based survey in 2 regions of the Republic of Moldova determined the incidence of fractures at the hip, proximal humerus and distal forearm. The estimated number of such fractures nationwide for 2015 was 11,271 and is predicted to increase to 15,863 in 2050 . The hip fracture rates were used to create a FRAX model to help guide decisions about treatment.

Objective This paper describes the epidemiology of osteoporotic fractures in Republic of Moldova that was used to develop the country-specific fracture prediction FRAX® tool.

Methods We carried out a retrospective population-based survey in 2 regions of the Republic of Moldova (Anenii Noi district and Orhei district) representing approximately $6 \%$ of the country's population. We identified hip, forearm and humerus fractures in 2011 and 2012 from hospital registers and primary care sources. Age- and sex-specific incidence of hip fracture and national mortality rates were incorporated into a FRAX model for Moldova. Fracture probabilities were compared with those from neighbouring countries having FRAX models.

Results The incidence of hip fracture applied nationally suggested that the estimated number of hip fractures nationwide in persons over the age of 50 years for 2015 was 3911 and is predicted to increase by $60 \%$ to 6492 in 2050 . Hip fracture incidence was a good predictor of forearm and humeral fractures. FRAX-based probabilities were higher in Moldova than neighbouring countries (Ukraine and Romania).
\end{abstract}

Conclusion The FRAX model should enhance accuracy of determining fracture probability among the Moldavan population and help guide decisions about treatment.

Keywords FRAX $\cdot$ Fracture probability $\cdot$ Epidemiology $\cdot$ Hip fracture

\section{Introduction}

The demographic transition caused by the increase in life expectancy and change in lifestyle pose challenges to modern health care systems due to the social and health problems

John A. Kanis

w.j.pontefract@sheffield.ac.uk

1 Ural State Medical University, 3 Repina street, Yekaterinburg, Russia 620028

2 North West State Medical University named after I.I. Mechnikov, 41, Kirochnaya street, St. Petersburg, Russia 191015

3 State University of Medicine and Pharmacy, 165 Stefan cel Mare si Sfant blvd., 2004 Chisinau, Republic of Moldova

4 Mary McKillop Health Institute, Catholic University of Australia, Melbourne, Australia associated with aging. Among these challenges is the rising prevalence of osteoporosis worldwide, and the colossal medical and economic consequences of fragility fractures. In Europe, the annual cost of fractures associated with osteoporosis exceeded $€ 37$ billion in 2010 [1] and disability due to

5 MRC Lifecourse Epidemiology Unit, University of Southampton, Southampton, UK

6 Centre for Metabolic Bone Diseases, University of Sheffield, Sheffield, UK

7 Geriatric Medicine, Department of Internal Medicine and Clinical Nutrition, Institute of Medicine, University of Gothenburg, Gothenburg, Sweden

8 Region Västra Götaland, Geriatric Medicine Clinic, Sahlgrenska University Hospital, Mölndal, Sweden 
fragility fracture was greater than that caused by any single cancer, with the exception of lung cancer. Disability was comparable or greater than that lost to a variety of chronic noncommunicable diseases, such as rheumatoid arthritis-, asthma- and high blood pressure-related heart disease [2]. In women over 45 years of age, fragility fractures account for more days spent in hospital than many other diseases, including diabetes, myocardial infarction and breast cancer [2].

Fortunately, a wide variety of treatments is available that favourably affect bone mass and thereby decrease the risk of fractures associated with osteoporosis [3]. The use of such interventions by health care practitioners is assisted by instruments that assess patients' fracture risk to optimise clinical decisions about prevention and treatment. The most widely used web-based tool FRAX® (https:/www.sheffield.ac.uk/ FRAX/) meets these requirements and computes the 10-year probability of low energy fractures based on several common clinical risk factors and, optionally, a DXA scan result $[4,5]$. Specifically, FRAX models compute the probabilities of major osteoporotic and hip fracture derived from the risk of fracture and the competing risk of death, both of which vary from country to country. The development of country-specific FRAX models requires information on fracture incidence and death [4]. Until recently, no FRAX model was available for Moldova due to the lack of appropriate epidemiological data. This paper describes the acquisition of data for the creation of a country-specific FRAX model for the Republic of Moldova.

\section{Methods}

The present study is a component part of the Multicenter Multinational population-based Study in Eurasian Countries (EVA study or ЭBA, in Russian). The broad aim of the study was to provide epidemiological information on fracture risk so that FRAX models could be created for Russia [6], Armenia [7], Belarus [8], Moldova, Kazakhstan and Uzbekistan. The present report describes the epidemiology of fractures at the hip, forearm and humerus in Moldova and the generation of a country-specific FRAX model.

The Republic of Moldova is a landlocked country in Eastern Europe bordered by Romania to the west and Ukraine to the north, east, and south. In 2010, the population of Moldova was 3,563,695 [9] but this excludes 520,786 people that lived in the breakaway state of Transnistria.

For the present study, we chose two areas of the country Anenii Noi and Orhei districts in central Moldova with a predominantly rural population. These districts were chosen for the ease of access to all medical records. The well-defined catchment areas ensured that the sources of medical record were comprehensive. The catchment population for the study period of 2011-2012 comprised 83,144 individuals from
Anenii Noi and 125,866 from Orhei. Thus, the total catchment population of the two regions was 209,010 representing $5.1 \%$ of the total population (or $5.6 \%$ excluding Transnistria). Eighty percent of the catchment population were from rural communities which is higher than the national average. According to the 2014 census, the percentage of Moldovans living in rural areas was $62 \%$ [9]. The age and sex distribution was very similar to that of the whole country. The ethnic distribution was Moldovan (85.5\%), Ukrainian (5.6\%), Romanian (4.6\%) and Russian (3.2\%) similar to that recorded in the national census of $2004(76 \%, 8.4 \%, 2.2 \%$, and $5.9 \%$ for Moldovans, Ukrainians, Romanians and Russians, respectively [9]).

The retrospective population-based study covered a 24month period from 1 January 2011 to 31 December 2012. In both locations, the medical records of all fractures in men and women aged 40 years or older were retrieved from the central city hospital registers (one hospital for each region), outpatient trauma units, and emergency services, 27 primary care centres and 2 private centres of medical care. The data on the following low energy fractures were collected: hip (ICD-10 codes S72.0, S72.1, S72.2), distal forearm (S52.5, S52.6) and proximal humerus fracture (S 42.2). Cases of high energy fractures were excluded from the analysis.

The reason for accessing multiple sources of information including that from primary care was to identify patients with hip fracture who were not admitted to hospital. The reason for this strategy was the observation that many patients in Eastern Europe are not hospitalized because facilities for surgical management are limited so that hospital admission is not feasible. In Belarus, for example, $29 \%$ cases of hip fracture did not come to hospital attention [8]. High rates of nonadmittance have been reported in Armenia (44\%) [7], Pervouralsk in Russia (27\%) [6], Georgia (75\%), Kazakhstan (50\%) and Kyrgyzstan (50\%) [10]. These missing cases from hospital discharge data reinforce a view that data on hip fracture based solely from hospital records are unreliable in this region of the world.

Only fractures validated by radiographs were included. To avoid double counting, further admissions for the same fracture site in the observation time were excluded. In some documents, fracture ICD-10 code was not specified. In such cases, radiographs were retrieved and verified fractures were included in the database. Permanent residence in the region was not a criterion for inclusion, so a small number of patients living temporarily in the catchment area $(n=33)$ were also included in the database. Yearly incidence rates were estimated from the number of men and women in 10-year age intervals with at least one index fracture in 2011 and 2012 divided by the age- and sex-specific population.

The age- and sex-specific incidence in 2011 and 2012 was applied to the Moldovan population for 2015 to estimate the number of hip, forearm and humeral fractures nationwide. 
Additionally, future projections were estimated up to 2050 assuming that the age- and sex-specific incidence remained stable. Population demography was taken from the United Nations using the medium variant for fertility [11].

The data on hip fracture were used to construct the FRAX model. For other major osteoporotic fractures (clinical spine, forearm and humeral fractures), it was assumed that the ageand sex-specific ratios of these fractures to hip fracture risk found in Sweden were comparable with those in Moldova. This assumption has been used for many of the FRAX models with incomplete epidemiological information. Available information suggests that the age- and sex-stratified pattern of fracture is very similar in the Western world and Australia [12-14]. In order to test this further, we compared the incidence of a forearm or humeral fracture observed in Moldova with the incidence that would be predicted from the pattern of incidence in Malmo applied to the incidence of hip fracture in Moldova. This assumes that the age- and sex-specific pattern of incidence of proximal humerus and forearm fracture (i.e. other major fractures; $\mathrm{OMF}$ ) and hip fracture (HF) in Moldova is similar to that seen in Malmo [12]. Thus, for each age and sex,

$\frac{\mathrm{HF}_{\text {Moldova }}}{\mathrm{HF}_{\text {Malmo }}}=\frac{\mathrm{OMF}_{\text {Moldova }}}{\mathrm{OMF}_{\text {Malmo }}}$

therefore,

$\mathrm{OMF}_{\text {Moldova }}=\frac{\mathrm{HF}_{\text {Moldova }} \times \mathrm{OMF}_{\text {Malmo }}}{\mathrm{HF}_{\text {Malmo }}}$

From this, the incidence of a forearm or humerus fracture, estimated using the Malmo ratios, was compared with the empirical data from Moldova. The analysis was confined to women where the numbers of fractures were higher.

The development and validation of FRAX have been extensively described $[4,5]$. The risk factors used were based on a systematic set of meta-analyses of populationbased cohorts worldwide and validated in independent cohorts with over 1 million patient-years of follow-up. The construct of the FRAX model for Moldova retained the beta coefficients of the risk factors in the original FRAX model with the incidence rates of hip fracture and mortality rates for Moldova. National mortality rates used data from the United Nations for 2009 [15]. Ten-year fracture probabilities were compared to those of neighbouring countries (Romania and Ukraine).

In order to compare Moldovan hip fracture probabilities with those of other regions of the world, the remaining lifetime probability of hip fracture from the age of 50 years was calculated for men and women, as described by Kanis et al. [16]. In the present analysis, values for Moldova were compared with those of Bulgaria, China (Hong Kong), Canada, Denmark, Finland, France, Greece, Kazakhstan, Poland, Portugal, Romania, Russia, Spain, Sweden, Turkey, Ukraine, the UK and the USA.

\section{Results}

In 2011-2012, a total of 1035 fractures were identified in individuals age 40 years or more. These comprised 340 hip fractures, 197 humerus and 494 distal forearm fractures.
Table 1 Population of the catchment areas, number of hip fractures and annual incidence of hip fractures (rate/100,000) in men and women in Moldova by age based on population data of from Anenii Noi and Orhei districts of Moldova for 2011 and 2012

\begin{tabular}{cllll}
\hline Age (years) & Population & Hip fractures* & $\begin{array}{l}\text { Incidence/ } \\
100,000\end{array}$ & \\
\hline Men & & & & \\
$40-49$ & 13,312 & 15 & 56.3 & CI \\
$50-59$ & 14,353 & 47 & 163.7 & $120.3-217.7$ \\
$60-69$ & 6827 & 36 & 263.7 & $184.6-365.1$ \\
$70-79$ & 3445 & 30 & 435.4 & $293.7-621.7$ \\
$80-89$ & 734 & 1 & 545.0 & $235.1-1074$ \\
$90+$ & 71 & 137 & 704.2 & $14.1-3929$ \\
$40+$ & 38,739 & & 176,83 & $148.4-209.0$ \\
Women & & 5 & 16.8 & \\
$40-49$ & 14,880 & 29 & 85.9 & $5.4-39.2$ \\
$50-59$ & 16,947 & 41 & 229.8 & $57.3-122.9$ \\
$60-69$ & 8921 & 69 & 596.0 & $164.9-311.8$ \\
$70-79$ & 5789 & 48 & 1211 & $463.7-754.3$ \\
$80-89$ & 1982 & 11 & 3481 & $892.8-1606$ \\
$90+$ & 158 & 203 & 208,53 & $1735-6230$ \\
$40+$ & 48,674 & & & $180.8-239.3$ \\
\hline
\end{tabular}

*Fractures over 2 years 
Table 2 Number and annual incidence of forearm and humeral fractures $($ rate/100,000) in men and women in Moldova by age based on population data of from Anenii Noi and Orhei districts of Moldova for 2011 and 2012

\begin{tabular}{|c|c|c|c|c|c|c|}
\hline \multirow[t]{2}{*}{ Age (years) } & \multicolumn{3}{|l|}{ Forearm } & \multicolumn{3}{|l|}{ Humerus } \\
\hline & Fractures* & Incidence & $95 \%$ CI & Fractures* & Incidence & $95 \% \mathrm{CI}$ \\
\hline \multicolumn{7}{|l|}{ Men } \\
\hline $40-49$ & 24 & 90 & $58-134$ & 5 & 19 & 6-44 \\
\hline $50-59$ & 53 & 185 & $138-242$ & 22 & 77 & $48-116$ \\
\hline $60-69$ & 25 & 183 & $118-270$ & 14 & 103 & $56-172$ \\
\hline $70-79$ & 8 & 116 & $50-299$ & 9 & 131 & $60-248$ \\
\hline $80-89$ & 1 & 68 & $1-380$ & 2 & 136 & $16-493$ \\
\hline $40+$ & 111 & 144 & $118-173$ & 52 & 67 & $50-88$ \\
\hline \multicolumn{7}{|l|}{ Women } \\
\hline $40-49$ & 35 & 118 & $82-164$ & 7 & 24 & $9-48$ \\
\hline $50-59$ & 151 & 446 & $377-523$ & 49 & 145 & $107-191$ \\
\hline $60-69$ & 120 & 673 & $558-804$ & 39 & 219 & 155-299 \\
\hline $70-79$ & 61 & 527 & $403-677$ & 39 & 337 & $239-461$ \\
\hline $80-89$ & 16 & 404 & $231-656$ & 11 & 277 & $138-497$ \\
\hline $40+$ & 383 & 395 & $356-436$ & 145 & 149 & $126-176$ \\
\hline
\end{tabular}

*Fractures over 2 years

\section{Hip fracture}

A total of 137 hip fractures were identified in men and 203 in women (female/male ratio 1.5). Below the age of 70 years, hip fractures were more prevalent in men than in women (female/ male ratio 0.8 ) but thereafter were more frequent in women (female/male ratio 3.3). The incidence of hip fracture increased with age in men and women, though more markedly in women (Table 1). Of the 340 cases with hip fractures, 334 were hospitalized.

\section{Forearm and humeral fractures}

Fractures at the distal forearm were more frequent in women than in men (female/male ratio $=3.5$ ). Fracture incidence in women rose with age up to the age of 69 years and thereafter decreased with age. In men, the incidence of forearm fractures decreased with age (Table 2). The annual incidence of proximal humerus fractures was lower in men than in women (female/male ratio $=2.8$ ). Humeral fractures were less common than forearm fractures and the association with age less secure.

\section{Fracture projections}

Assuming that the fracture rates in Anenii Noi and Orhei districts were representative for the whole country, and based on the UN estimates of Moldavan population for 2015, we estimated that the annual number of all three types of fracture in men and women age 50 years and older in Moldova in 2015 was 11,271, comprising 3911 hip fractures, 5216 distal forearm fractures and 2144 humerus fractures. The number of fractures is expected to increase progressively over calendar year with an increase of $41 \%$ for the three fracture sites by 2050 (Table 3). The increase in hip fracture numbers is particularly great in women $(81 \%)$ due to the high age dependency of hip fracture incidence.

\section{Fracture probability}

The incidence of forearm and humeral fractures was very similar to that predicted from the epidemiology of fracture in Malmo (Table 4) and the Malmo ratios were used for the construct of FRAX. Overall, the incidence of fractures at the

Table 3 Estimated total number of hip forearm and humerus fractures in men and in women age 50 years and older in 2015 projected up to 2050 in Moldova

\begin{tabular}{|c|c|c|c|c|c|}
\hline & 2015 & 2020 & 2030 & 2040 & 2050 \\
\hline \multicolumn{6}{|c|}{ Hip fracture ${ }^{a}$} \\
\hline Men & 1359 & 1375 & 1526 & 1644 & 1818 \\
\hline Women & 2381 & 2617 & 3177 & 3813 & 4359 \\
\hline \multicolumn{6}{|c|}{ Forearm fracture ${ }^{\mathrm{b}}$} \\
\hline Men & 914 & 875 & 903 & 1146 & 1127 \\
\hline Women & 3789 & 3986 & 4258 & 4772 & 4953 \\
\hline \multicolumn{6}{|c|}{ Humerus fracture $^{c}$} \\
\hline Men & 513 & 513 & 542 & 651 & 714 \\
\hline Women & 1528 & 1571 & 1806 & 2041 & 2113 \\
\hline Totals & 10,484 & 10,937 & 12,212 & 14,067 & 15,084 \\
\hline
\end{tabular}

${ }^{\mathrm{a}}$ Hip (ICD-10 codes S72.0, S72.1, S72.2)

${ }^{\mathrm{b}}$ Distal forearm (ICD-10 codes S52.5, S52.6)

${ }^{\mathrm{c}}$ Humerus (ICD-10 code S 42.2) 
Table 4 The incidence of forearm and humeral fractures in women predicted from the epidemiology in Malmo (see methods) and that observed in the present study with 95\% confidence intervals (CI).

The observation in bold denote a difference between observed and predicted estimates

\begin{tabular}{|c|c|c|c|c|c|c|}
\hline \multirow[t]{2}{*}{ Age (years) } & \multicolumn{3}{|l|}{ Forearm } & \multicolumn{3}{|l|}{ Humerus } \\
\hline & Predicted & Observed & $95 \%$ CI & Predicted & Observed & $95 \% \mathrm{CI}$ \\
\hline $50-54$ & 447 & 412 & $324-516$ & 133 & 99 & 59-156 \\
\hline $55-59$ & 671 & 485 & $382-607$ & 188 & 198 & $134-281$ \\
\hline $60-64$ & 590 & 705 & $558-879$ & 132 & 250 & $166-361$ \\
\hline $65-69$ & 539 & 617 & $443-838$ & 274 & 166 & 83-296 \\
\hline $70-74$ & 606 & 560 & $397-769$ & 257 & 324 & $203-491$ \\
\hline $75-79$ & 407 & 479 & $304-720$ & 247 & 354 & $206-568$ \\
\hline $80-84$ & 468 & 407 & $203-729$ & 220 & 296 & $128-584$ \\
\hline $85-89$ & 278 & 397 & $128-925$ & 227 & 238 & 49-695 \\
\hline
\end{tabular}

distal forearm and humerus was well predicted by the use of the Malmo ratios to hip fracture incidence from Moldova. The exception in women for forearm fracture was at the ages of 55-59 years where the use of Malmo ratios overestimated the observed incidence. At other ages, the estimates lay within the $95 \%$ confidence intervals of the empirical data. For humerus fracture in women, the exception was between the ages of 60 64 years where the use of Malmo ratios underestimated the observed incidence.

The 10-year probability of major osteoporotic fracture and hip fracture in Moldova and neighbouring countries is shown in Fig. 1 in women with a prior fracture by age. Ten-year probabilities were consistently higher than in the neighbouring countries of Ukraine and Romania.

Lifetime probabilities for hip fracture are shown in Table 5.

\section{Discussion}

This study documented the incidence of hip, distal forearm and proximal humeral fragility fractures in Moldova based on regional estimates from two districts. As expected, hip fractures were more frequent in women than in men (female/male ratio $=1.48$ ). In both sexes, the incidence increased with age. It is of interest that for people younger than 70 years, the hip fracture rate among men was higher than in women. Thereafter, incidence was higher in women. Similar results have been reported in many studies including other countries of the EVA project, namely Russia, Armenia and Belarus [6-9]. From these results, Moldova belongs to the moderate-risk countries for osteoporotic hip fracture for men and women [22].

Based on the regional incidence, the number of hip fractures in 2015 was estimated at 3911 and is expected to increase by $65 \%$ to 6492 in 2050 . These estimates are relatively robust in that all individuals who will be aged 60 years or more in 2050 are currently adults. However, these estimates may be conservative since they assume that the age- and sex-specific risk of hip fracture remains unchanged over this period. Decreases in agespecific rates have occurred in those countries with the higher hip fracture risks [23], whereas increases in incidence with time are commonly found in those countries with the lower risks. It is estimated that modest increases in secular trends (e.g. 1\% per year) as seen for example in Mexico [24] together with demographic changes would double the number of hip fractures over 20 years [25]. For hip, humerus and forearm fractures combined, the numbers anticipated will increase by $41 \%$. Such projections are important for health care planning.

Ten-year probabilities were consistently higher than in the neighbouring countries of Ukraine and Romania. These differences in fracture probability cannot be accounted for by differences in mortality but rather, reflect differences in the risk of hip fracture. Reasons for the heterogeneity in hip fracture risk are speculative [24]. The factor which best predicts the heterogeneity in hip fracture risk is socioeconomic
Fig. 1 10-year probability of a major osteoporotic fracture (left hand panel) and hip fracture (right) in women with a prior fracture by age from Moldova, Ukraine and Romania. Body mass index set to $25 \mathrm{~kg} / \mathrm{m}^{2}$
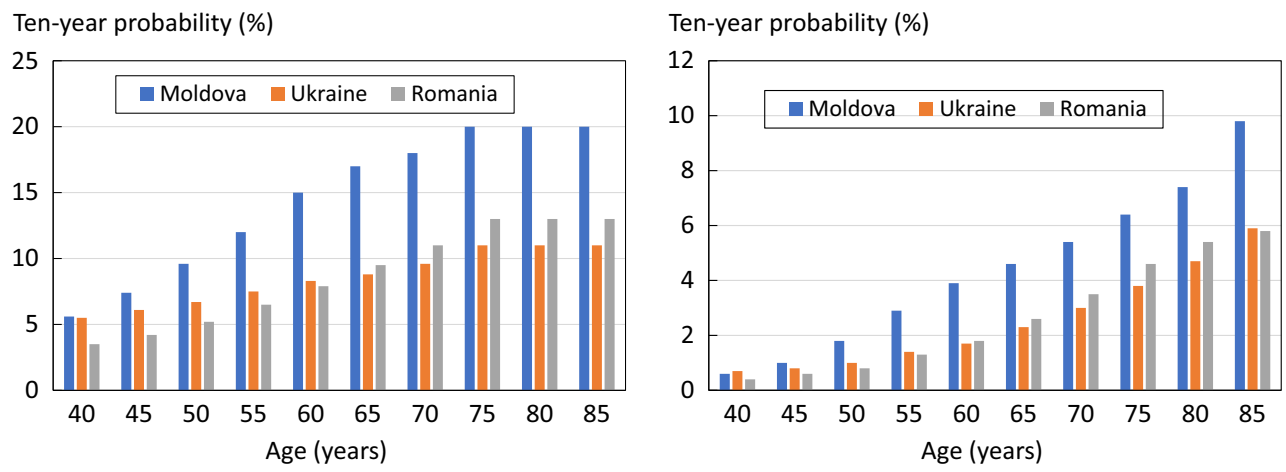
Table 5 Lifetime probability of hip fracture in the Moldovan population from the age of 50 years compared with selected countries. From [16] except where indicated

\begin{tabular}{|c|c|c|}
\hline \multirow[t]{2}{*}{ Country } & \multicolumn{2}{|c|}{ Lifetime risk at 50 years $\%$} \\
\hline & Women & Men \\
\hline Sweden & 25.6 & 11.0 \\
\hline Denmark & 23.0 & 11.3 \\
\hline France & 19.3 & 5.9 \\
\hline China (Hong Kong) & 17.7 & 7.6 \\
\hline USA (Caucasian) & 16.1 & 7.5 \\
\hline Turkey $^{\text {a }}$ & 15.9 & 3.6 \\
\hline Canada & 15.5 & 5.8 \\
\hline Greece & 15.4 & 6.8 \\
\hline UK & 14.4 & 5.0 \\
\hline Portugal & 13.7 & 4.8 \\
\hline Finland & 12.9 & 6.0 \\
\hline Kazakhstan & 12.6 & 6.0 \\
\hline Spain & 12.6 & 4.2 \\
\hline Bulgaria & 11.2 & 4.4 \\
\hline Hungary & 10.8 & 4.2 \\
\hline Mexico $^{b}$ & 10.6 & 5.0 \\
\hline Poland ${ }^{\mathrm{f}}$ & 10.1 & 4.2 \\
\hline Moldova $^{\mathrm{e}}$ & 9.3 & 5.7 \\
\hline Russia $^{c}$ & 7.7 & 3.8 \\
\hline Romaia $^{\mathrm{d}}$ & 7.0 & 3.8 \\
\hline Ukraine $^{\mathrm{g}}$ & 5.6 & 2.9 \\
\hline
\end{tabular}

${ }^{\mathrm{a}}$ [17]; ${ }^{\mathrm{b}}[18] ;{ }^{\mathrm{c}}[6] ;{ }^{\mathrm{d}}[19] ;{ }^{\mathrm{e}}$ This study; ${ }^{\mathrm{f}}$ [20]; ${ }^{\mathrm{g}}$ [21]

prosperity that in turn may be related to low levels of physical activity [26]. The fact that there are differences in adjacent countries emphasizes the importance of the use of countryspecific FRAX models rather than surrogate models [27].

A minority of countries that have a FRAX model also have robust information on the risk of other major osteoporotic fractures. In the absence of such information, FRAX models are based on the assumption that the age- and sex-specific pattern of these fractures is similar to that observed in Malmo [28]. The acquisition of data on the incidence of forearm and humerus fractures in a manner identical to that for hip fracture permitted the adequacy of this assumption to be tested, at least for forearm and humeral fractures. Our findings suggest that the incidence of forearm and humerus fractures can be reasonably predicted from the incidence of hip fracture. Very similar findings have been reported from Canada [14], Iceland [13], the USA [29], the UK [30], Australia [31] and several additional counties of the Western world, despite differences in incidence [28, 32]. This commonality of pattern is supported by register studies, which indicate that in those regions where hip fracture rates are high, so too is the risk of forearm fracture and spine fractures (requiring hospital admission) [33, 34]. To our knowledge, the present study is the first to report the commonality of fracture pattern in Eastern Europe.

There are a number of limitations to this study. With regard to fracture incidence, we examined only about $5 \%$ of the Moldovan population. Therefore, the extrapolation of these regional estimations to the entire country is an assumption that we were unable to test. In addition to large variations in fracture rates around the world, fracture rates may vary within countries. In addition to ethnic-specific differences [35], up to two-fold differences in hip fracture incidence have been reported using common methodology with the higher rates in urban communities including Croatia [36], Switzerland [37], Norway [38], Argentina [39] and Turkey [40].

Despite the rigour of the methodology and welldefined catchment population, it is possible that not all hip fractures were captured. It is relevant, however, that accuracy errors have little impact on the rank order with which the FRAX tool categorizes risk in a given population [7, 41] but they do change the absolute number generated and thus have implications where treatment guidelines are based on cost-effectiveness or the economic burden of disease. In order to address these limitations, representative populations representative of the general population at risk would need to be studied prospectively, preferably over a 10 -year time horizon.

In summary, a FRAX model has been created for the Republic of Moldova that based on a regional populationbased estimates of the incidence of low energy hip fractures. The model should enhance accuracy of determining fracture probability among the Moldavan population and help to guide decisions about treatment.

Acknowledgements The authors would like to thank the administration of Orhei and Anenii Noi county hospitals for their support.

Funding information The project did not receive specific funding. Servier, however, is acknowledged in helping with organization of the EVA project; "Epidemiology of osteoporotic fractures in Eurasian counties" study (EVA or ЭBA, in Russian), of which this is one of the outcomes.

\section{Compliance with ethical standards}

All procedures performed in studies involving human participants were conducted in accordance with the ethical standards of the institutional and national research committee and with the 1964 Helsinki Declaration and its later amendments or compatible ethical standards.

Conflict of interest None.

Open Access This article is distributed under the terms of the Creative Commons Attribution 4.0 International License (http:// creativecommons.org/licenses/by/4.0/), which permits unrestricted use, distribution, and reproduction in any medium, provided you give appropriate credit to the original author(s) and the source, provide a link to the Creative Commons license, and indicate if changes were made. 


\section{References}

1. Hernlund E, Svedbom A, Ivergård M Compston J, Cooper C, Stenmark J, McCloskey EV, Jönsson B, Kanis JA (2013) Osteoporosis in the European Union: medical management, epidemiology and economic burden. A report prepared in collaboration with the International Osteoporosis Foundation (IOF) and the European Federation of Pharmaceutical Industry Associations (EFPIA). Archives of Osteoporosis 8:136

2. Johnell O, Kanis JA (2006) An estimate of the worldwide prevalence and disability associated with osteoporotic fractures. Osteoporos Int 17:1726-1733

3. Kanis JA, Cooper C, Rizzoli R, Reginster J-Y; Scientific Advisory Board of the European Society for Clinical and Economic Aspects of Osteoporosis (ESCEO) and the Committees of Scientific Advisors and National Societies of the International Osteoporosis Foundation (IOF) (2019) European guidance for the diagnosis and management of osteoporosis in postmenopausal women. Osteoporos Int 30: 3-44

4. Kanis JA on behalf of the World Health Organization Scientific Group (2008) Assessment of osteoporosis at the primary healthcare level. Technical report. WHO Collaborating Centre, University of Sheffield, UK. Available at . http://www.shef.ac.uk/FRAX/pdfs/ WHO_Technical_Report.pdf.

5. Kanis JA, Johnell O, Oden A, Johansson H, McCloskey E (2008) FRAX $^{\mathrm{TM}}$ and the assessment of fracture probability in men and women from the UK. Osteoporos Int 19:385-397

6. Lesnyak O, Ershova O, Belova K, Gladkova E, Sinitsina O, Ganert O, Romanova M, Khodirev V, Johansson H, McCloskey E, Kanis JA (2012) Epidemiology of fracture in the Russian Federation and the development of a FRAX model. Arch Osteoporos 7:67-73. https://doi.org/10.1007/s11657-012-0082-3

7. Lesnyak O, Sahakyan S, Zakroyeva A, Bilezikian JP, Hutchings N, Galstyan R, Lebedev A, Johansson H, Harvey NC, McCloskey E, Kanis JA (2017) Epidemiology of fractures in Armenia: development of a country-specific FRAX model and comparison to its surrogate. Arch Osteoporos 12(1):98. https://doi.org/10.1007/ s11657-017-0392-6

8. Ramanau H, Chernyanin I, Rudenka E, Lesnyak O, Zakroyeva A, Bilezikian JP, Johansson H, Harvey NC, McCloskey EV, Kanis JA (2018) Epidemiology of hip fracture in Belarus: development of a country-specific FRAX model and its comparison to neighboring country models. Arch Osteoporos 13:42. https://doi.org/10.1007/ s11657-018-0454-4

9. Statistica Moldovei (2019) National Bureau of Statistics of the Republic of Moldova. http://statbank.statistica.md/pxweb/pxweb/ en/?rxid=aacc043f-c3cb-4c88-9ac7-5390459f620c. Accessed 26th March 2019

10. International Osteoporosis Foundation (2011) The Eastern European \& Central Asian Regional Audit. Epidemiology, costs \& burden of osteoporosis in 2010. Naturaprint, France. Available at https://www.iofbonehealth.org/sites/default/files/PDFs/Audit\% 20Eastern\%20Europe Central\%20Asia/Eastern European Central Asian Audit 2010.pdf.

11. United Nations (2017) DESA / population division. World Population Prospects 2017 https://population.un.org/wpp/ Download/Standard/Population/.

12. Kanis JA, Oden A, Johnell O, Jonsson B, de Laet C, Dawson A (2001) The burden of osteoporotic fractures: a method for setting intervention thresholds. Osteoporos Int 12:417-427

13. Siggeirsdottir K, Aspelund T, Johansson H, Gudmundsson EF, Mogensen B, Jonsson BY, Gudnason V, McCloskey E, Oden A, Sigurdsson G, Kanis JA (2014) The incidence of a first major osteoporotic fracture in Iceland and implications for FRAX. Osteoporos Int 25:2445-2451
14. Lam A, LeslieWD LLM, Yogendran M, Morin SN, Majumdar SR (2014) Major osteoporotic to hip fracture ratios in Canadian men and women with Swedish comparisons: a population-based analysis. J Bone Miner Res 29:1067-1073

15. United Nations (2010) Population Division of the Department of Economic and Social Affairs of the United Nations Secretariat, World Population Prospects: http://esa.un.org/unpd/wpp/unpp/ panel_indicators.htm Accessed November 2011

16. Kanis JA, Johnell O, De Laet C, Jonsson B, Oden A, Ogelsby AK (2002) International variations in hip fracture probabilities: implications for risk assessment. J Bone Miner Res 17:1237-1244

17. Tuzun S, Eskiyurt N, Akarırmak U, Sarıdoğan M, Senocak M, Johansson H, Kanis JA and the Turkish Osteoporosis Society (2012) Incidence of hip fracture and prevalence of osteoporosis in Turkey: the FRACTURK study. Osteoporos Int 23:949-955

18. Clark P, Lavielle P, Franco-Morina F, Ramirez E, Salmeron J, Kanis JA, Cummings SR (2005) Incidence rates and life-time risk of hip fractures in Mexicans over 50 years of age: a population-based study. Osteoporos Int 16:2025-2030

19. Grigorie D, Sucaliuc A, , Johansson H, Kanis JA, McCloskey E (2013) Incidence of hip fracture in Romania and the development of a Romanian FRAX model. Calcif Tiss Int 92:429-436

20. Czerwinski E, Kanis JA, Trybulec B, Johansson H, Borowy P, Osieleniec J (2009) The incidence and risk of hip fracture in Poland. Osteoporos Int 20:1363-1367

21. Povoroznyuk VV, Grygorieva NV, Kanis JA, McCloskey EV, Johansson H, Harvey NC, Korzh MO, Strafun SS, Vaida VM, Klymovytsky FV, Vlasenko RO, Forosenko VS (2017) Epidemiology of hip fracture and the development of FRAX in Ukraine. Arch Osteoporos 12:53

22. Kanis JA, Oden A, McCloskey EV, Johansson HD, Wahl A, Cooper C (2012) A systematic review of hip fracture incidence and probability of fracture worldwide. Osteoporos Int 23(9): 2239-2256

23. Cooper C, Cole ZA, Holroyd CR, Earl SC, Harvey NC, Dennison EM Melton LJ3, Cummings SR, Kanis JA and the IOF CSA Working Group on Fracture Epidemiology (2011) Secular trends in the incidence of hip and other osteoporotic fractures. Osteoporos Int 22:1277-1288

24. Johansson H, Clark P, Carlos F, Oden A, McCloskey EV, Kanis JA (2011) Increasing age- and sex-specific rates of hip fracture in Mexico: a survey of the Mexican institute of social security. Osteoporos Int 22:2359-2364

25. Gullberg B, Johnell O, Kanis JA (1997) World-wide projections for hip fracture. Osteoporos Int 7:407-413

26. Johnell O, Borgstrom F, Jonsson B, Kanis J (2007) Latitude, socioeconomic prosperity, mobile phones and hip fracture risk. Osteoporos Int 18:333-337

27. Cauley JA, El-Hajj Fuleihan G, Arabi A, Fujiwara S, Ragi-Eis S, Calderon A, Chionh SB, Chen Z, Curtis JR, Danielson ME, Hanley DA, Kroger H, Kung AW, Lesnyak O, Nieves J, Pluskiewicz W, El Rassi R, Silverman S, Schott AM, Rizzoli R, Luckey M; FRAX® Position Conference Members (2011) Official positions for FRAX clinical regarding international differences from Joint Official Positions Development Conference of the International Society for Clinical Densitometry and International Osteoporosis Foundation on FRAX. J Clin Densitom 14(3): 240e262

28. Kanis JA, Hans D, Cooper C, Baim S, Bilezikian JP, Binkley N, Compston J, Dawson-Hughes B, El-Hajj Fuleihan G, Johansson H, Leslie WD, Lewiecki EM, Luckey MM, Oden A, Papapoulos SE, Poiana C, Wahl DA, McCloskey E, and the Task Force of the FRAX Initiative (2011) Interpretation and use of FRAX in clinical practice. Osteoporos Int 22:395-411

29. Melton LJ, Crowson CS, O'Fallon WM (1999) Fracture incidence in Olmsted County, Minnesota: comparison of urban and with rural rates and changes in urban rates over time. Osteoporos Int 9:29-37 
30. Singer BR, McLauchlan CJ, Robinson CM, Christie J (1998) Epidemiology of fracture in 15.000 adults. The influence of age and gender. J Bone Joint Surg 80B:234-238

31. Sanders KM, Seeman E, Ugoni AM, Pasco JA, Martin TJ, Skoric B, Nicholson GC, Kotowicz MA (1999) Age- and gender specific rate of fractures in Australia: a population-based study. Osteoporos Int 10(2):40-47

32. Kanis JA, Johnell O, Oden A, Sernbo I, Redlund-Johnell I, Dawson A, de Laet C, Jonsson B (2000) Long-term risk of osteoporotic fractures in Malmo. Osteoporos Int 11:669-674

33. Johnell O, Gullberg B, Kanis JA (1997) The hospital burden of vertebral fracture in Europe: a study of national register sources. Osteoporos Int 7:138-144

34. Melton LJ (1995) Epidemiology of fractures. In: Riggs BL, Melton LJ (eds) Osteoporosis: etiology, diagnosis and management, 2ndedn. Lippincott-Raven, Philadelphia, pp 225-227

35. Cauley JA, Chalhoub D, Kassem AM, Fuleihan G el-H (2014) Geographic and ethnic disparities in osteoporotic fractures. Nat Rev Endocrinol 10: 338-351

36. Karacić TP, Kopjar B (2009) Hip fracture incidence in Croatia in patients aged 65 years and more. Lijec Vjesn 131:9-13
37. Lippuner K, Johansson H, Kanis JA, Rizzoli R (2010) FRAX assessment of osteoporotic fracture probability in Switzerland. Osteoporos Int 21:381-389

38. Emaus N, Olsen LR, Ahmed LA, Balteskard L, Jacobsen BK, Magnus T, Ytterstad B (2011) Hip fractures in a city in Northern Norway over 15 years: time trends, seasonal variation and mortality: the Harstad Injury Prevention Study. Osteoporos Int 22:26032610

39. Morosano M, Masoni A, Sánchez A (2005) Incidence of hip fractures in the city of Rosario. Argentina: Osteoporos Int 16:13391344

40. Elffors L, Allander E, Kanis JA, Gullberg B, Johnell O, Dequeker J, Dilzen G, Gennari C, Lopez-Vaz AA, Lyritis G, Mazzuoli GF, Miravet L, Passeri M, Perez Cano R, Rapado A, Ribot C (1994) The variable incidence of hip fracture in Southern Europe. The MEDOS study. Osteoporos Int 4:253-263

41. Kanis JA, Johansson H, Oden A, Dawson-Hughes B, Melton LJ 3rd, McCloskey EV (2010) The effects of a FRAX® revision for the USA. Osteoporos Int 21:35-40

Publisher's note Springer Nature remains neutral with regard to jurisdictional claims in published maps and institutional affiliations. 